\title{
DNA Transfection Screening from Single Beads
}

\author{
Boon-ek Yingyongnarongkul, ${ }^{\dagger}$ Mark Howarth, ${ }^{\ddagger}$ Tim Elliott, ${ }^{\ddagger}$ and Mark Bradley*, ${ }^{\dagger}$ \\ Department of Chemistry, University of Southampton, Southampton SO17 1BJ, U.K., and \\ Cancer Sciences Division, University of Southampton School of Medicine, \\ Southampton General Hospital, SO16 6YD, U.K.
}

Received March 4, 2004

\begin{abstract}
The solid-phase synthesis of a library of arginine-containing lipid transfection agents on high-loading beads is described. The transfection activity of the cationic lipids was determined using compound cleaved from single beads (single-bead screening) and showed, in some cases, comparable or higher DNA transfection activities as compared to commercially available reagents. Lipids with one arginine headgroup and a cholesterol tail were found to be the most active, even though their DNA binding strength (retardation assays) was relatively weak. Single-bead screening of transfection activity facilitates the rapid analysis of libraries of transfection reagents and will allow the rapid optimization of gene delivery into cells, both in culture and in vivo.
\end{abstract}

\section{Introduction}

Over recent years combinatorial chemistry methods have revolutionized the synthesis of small organic compounds. ${ }^{1}$ Many strategies have been applied, but two methods, parallel and split-and-mix synthesis, occupy a dominant position. Of these two approaches, split-and-mix synthesis is certainly more compelling in terms of the time and the overall cost and the size of libraries that can be prepared, ${ }^{2}$ but parallel synthesis $^{3}$ is the major method currently used in library generation. The one-bead/one-compound combinatorial approach is, however, highly efficient, ${ }^{4}$ enabling the generation of thousands or millions of compounds in only a small number of synthetic steps, although the quantity of material on a single bead is relatively limited, and identification of active compounds at the single bead level can be difficult. These problem can be solved first by increasing the loading of each single bead and second by developing sensitive methods to screen for compound activity.

Methods to increase bead loading for single-compound/ single-bead stock solution screening were first reported in 1997 using a process of PAMAM dendrimerization, ${ }^{5}$ and more recently, $\mathrm{AB}_{3}$-type isocyanate monomers have proven to be high advantageous building blocks to increase the loading of a solid support due to their high branching multiplicity and the presence of a reactive isocyanate group. ${ }^{6-8}$ Thus, repeated coupling of monomer 1 (Figure 1) onto $200-250-\mu \mathrm{m}$ aminomethyl polystyrene beads $(13 \mathrm{nmol} /$ bead) increases the loading of the beads by 2.8 -fold $(36 \mathrm{nmol} /$ bead) and 6.9-fold (90 nmol/bead) (generation 1.0 and 2.0), respectively. ${ }^{8}$ In this paper, transfection agents were synthesized on these high-loading beads using solid-phase synthesis to allow sufficient compound to be released from single beads for transfection screening.

\footnotetext{
* Corresponding author. E-mailmb14@soton.ac.uk.

$\dagger$ Department of Chemistry.

$\doteqdot$ Cancer Sciences Division, University of Southampton School of Medicine.
}

There is still a significant need for the development of new, nonviral, transfection reagents for the study of gene function using cells in culture ${ }^{9}$ and for therapeutic gene delivery in vivo. ${ }^{10}$ Cationic lipids for transfection generally contain a cationic headgroup attached to a hydrophobic tail. Arginine-containing lipids have been shown to transfect COS-7 cells,${ }^{11}$ with the guanidinium group interacting with the negatively charged phosphate groups of the oligonucleotide and also presumably with the cell membrane. Short oligomers of arginine have also been shown to enter cells more rapidly than the corresponding oligomers of lysine, histidine, ornithine, or citrulline. ${ }^{12}$ Thus, a library of cationic lipids possessing a guanidine headgroup linked to various aliphatic or steroidal tail groups was synthesized. Compounds were cleaved from single beads and tested for transfection activity and cytotoxicity and other factors affecting the activity of the most efficient compounds were determined.

\section{Results and Discussion}

Synthesis of Transfection Compounds on High-Loading Beads. High-loading beads of type 2 (generation 1.0) were generated using an $\mathrm{AB}_{3}$-type isocyanate monomer $(\mathbf{1})^{8}$ (Figure 1) attached directly onto the aminomethyl polystyrene resin.

Scaffolds with one, two, or three arginine headgroups (57) were synthesized on these beads (Scheme 1) using Fmoc chemistry. Thus high-loading beads (2, Gen 1.0$)$ were reacted with the commercially available Fmoc Knorr linker 3, which was Fmoc-deprotected to give 4, which was coupled with commercially available Fmoc-arginine(Boc $)_{2}-\mathrm{OH}$, followed by Fmoc deprotection. The process was repeated to give $\mathbf{6}$ and 7 (Scheme 1).

The spacer between the cationic headgroup and the hydrophobic moiety plays a key role in transfection activity. ${ }^{13}$ It has been shown that cationic lipids containing biodegradable ester spacers have high transfection efficiency and low cytotoxicity, ${ }^{14,15}$ whereas Kawaura ${ }^{16}$ found that the transfec- 


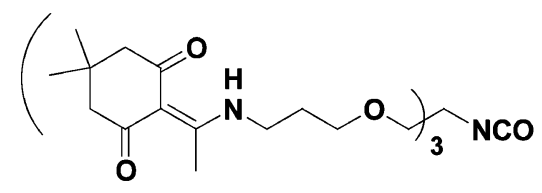

1

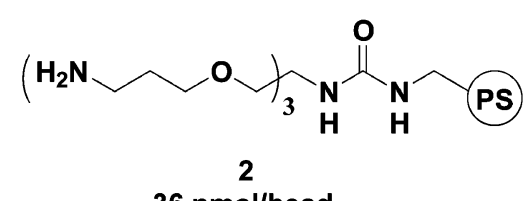

$36 \mathrm{nmol} / \mathrm{bead}$

Figure 1. Structures of $\mathrm{AB}_{3}$-type monomer and high-loading polystyrene (PS) bead (generation 1.0).

Scheme $1^{a}$

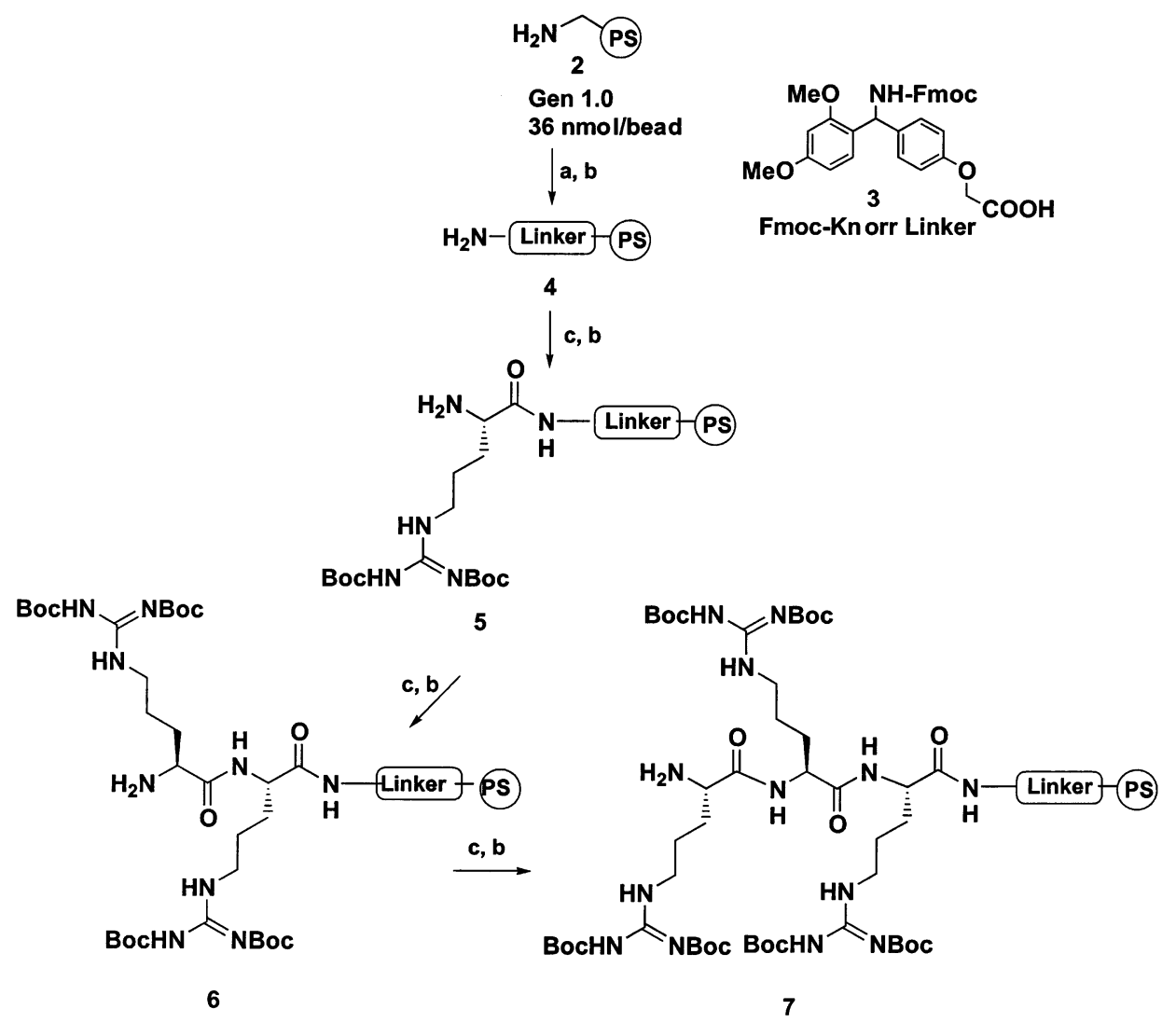

${ }^{a}$ Reagents and conditions: (a) linker 3 (1.5 equiv), DIC (1.5 equiv), HOBt (1.5 equiv), $\mathrm{CH}_{2} \mathrm{Cl}_{2} / \mathrm{DMF}$; (b) $20 \%$ piperidine/DMF, $2 \times 10 \mathrm{~min}$; (c) Fmoc- $\mathrm{Arg}(\mathrm{Boc})_{2}-\mathrm{OH}$ (1.5 equiv), DIC (1.5 equiv), $\mathrm{HOBt}$ (1.5 equiv), $\mathrm{CH}_{2} \mathrm{Cl}_{2} / \mathrm{DMF}$.

$$
\mathrm{FmocHN} \widehat{\mathrm{COOH}}
$$$$
\text { Fmoc-Gly-OH }
$$

$$
\text { FmocHN } \mathrm{COOH}
$$$$
\text { Fmoc- } \beta \text {-Ala-OH }
$$

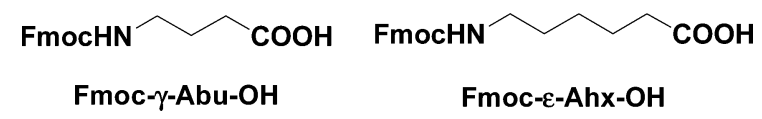

Figure 2. Fmoc amino acids used as a spacer between the cationic headgroup and the hydrophobic tail.

tion efficiency was dependent on the length of the spacer between the cationic headgroup and the hydrophobic tail. Thus, four different commercially available amino acids spacers, with 1, 2, 3, or 5 carbons between the amine and carboxylic acid functionality (Figure 2) were attached to 5-7 to afford the arginine scaffolds with various spacers 8-11 (Scheme 2).

With the 15 scaffolds in hand (3 scaffolds without spacers (5-7, Scheme 1) and 12 scaffolds with spacers (8-11, Scheme 2)), a small library was constructed as shown in Scheme 3 (15 arginine scaffolds $\times 4$ hydrophobic tails $=$ 60 compounds) to enable initial evaluation of the single bead screening methods. Cleavage and concomitant deprotection with $90 \%$ TFA in $\mathrm{CH}_{2} \mathrm{Cl}_{2}$ from a single bead furnished sufficient material for LC and MS analysis (high-resolution mass spectrometry characterization was performed on the library). The average purity of the compounds was $83 \%$ (HPLC).

Gel Retardation Assay. ${ }^{17}$ To assess the relative binding activities of the transfection compounds for DNA, agarose gel electrophoresis of cationic lipid/DNA complexes was performed using compound cleaved from a single bead, and 38 of the 60 compounds completely bound plasmid DNA (Figure 4). The number of arginine residues and the type of hydrophobic tail had a major effect on complex formation, but the spacer appeared to have little effect. Transfection compounds containing one arginine $(\mathbf{A 1}, \mathbf{2}, \mathbf{4} ; \mathbf{B 1}, \mathbf{2}, \mathbf{4} ; \mathbf{C 1}$, 2, 4; D1, 2, 4; and E1, 2, 4; Scheme 3 and Table 1) did not bind DNA unless an oleyl tail group was present (A3, B3, C3, D3 and E3), irrespective of the spacer employed. Transfection compounds containing two arginines and aliphatic tails (F1-F3, G1-G3, H1-H3, A5-A7, and B5B7) all retarded the DNA, unlike compounds with two arginines and a cholesterol tail (F4, G4, H4, A8, B8). 
Scheme $2^{a}$

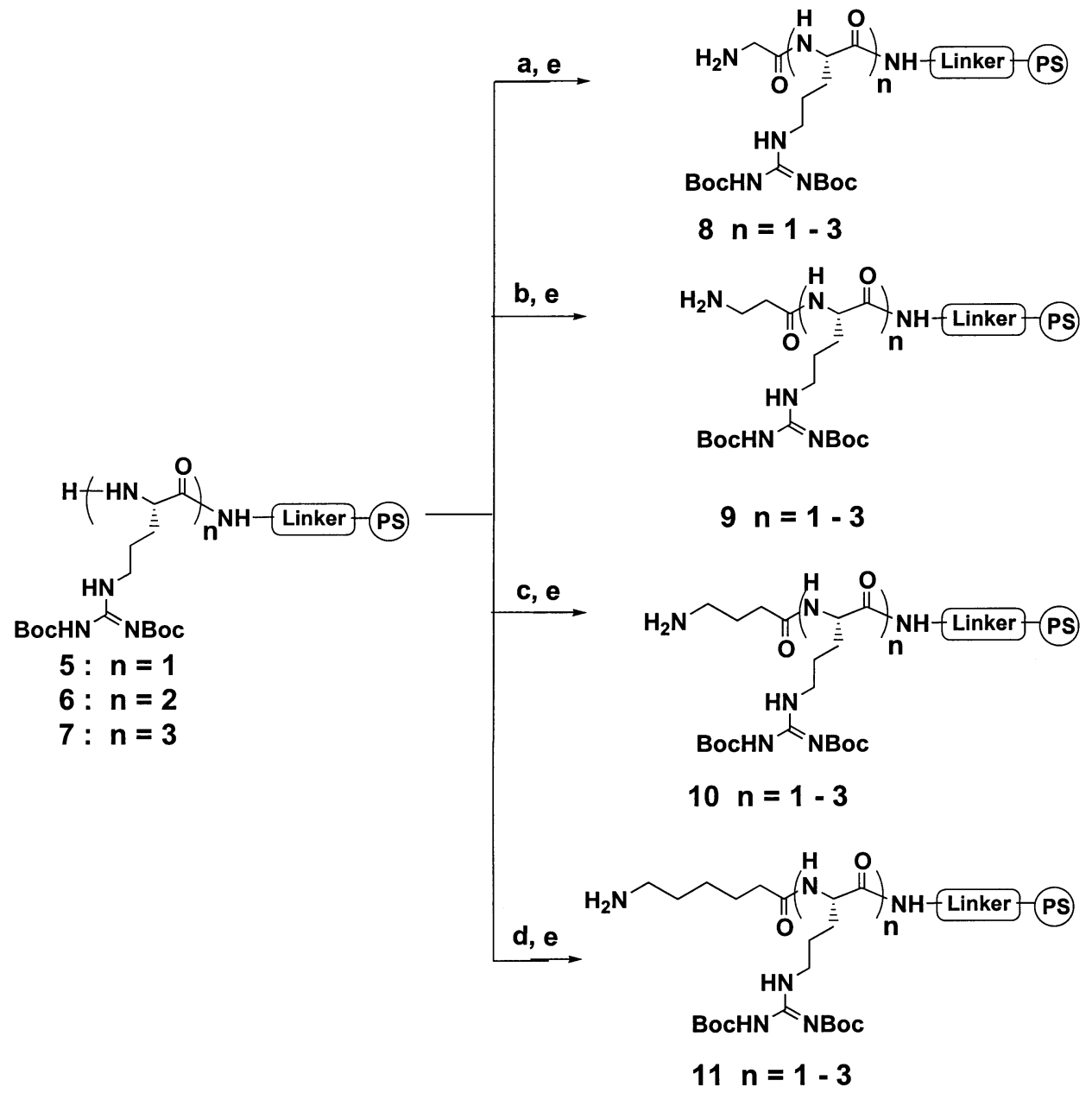

${ }^{a}$ Reagents and conditions: (a) Fmoc-Gly-OH (1.5 equiv), DIC (1.5 equiv), $\mathrm{HOBt}$ (1.5 equiv), $\mathrm{CH}_{2} \mathrm{Cl}_{2} / \mathrm{DMF}$; (b) Fmoc- $\beta$-Ala- $\mathrm{OH}$ (1.5 equiv), DIC (1.5 equiv), $\mathrm{HOBt}$ (1.5 equiv), $\mathrm{CH}_{2} \mathrm{Cl}_{2} / \mathrm{DMF}$; (c) Fmoc- $\gamma$ - $\mathrm{Abu}-\mathrm{OH}$ (1.5 equiv), DIC (1.5 equiv), $\mathrm{HOBt}$ (1.5 equiv), $\mathrm{CH}_{2} \mathrm{Cl} / 2 / \mathrm{DMF}$; (d) Fmoc- $\epsilon-\mathrm{Ahx}-\mathrm{OH}$ (1.5 equiv), DIC (1.5 equiv), $\mathrm{HOBt}$ ( 1.5 equiv), $\mathrm{CH}_{2} \mathrm{Cl}_{2} / \mathrm{DMF}$; (e) $20 \%$ piperidine/DMF.

\section{Scheme $3^{a}$}
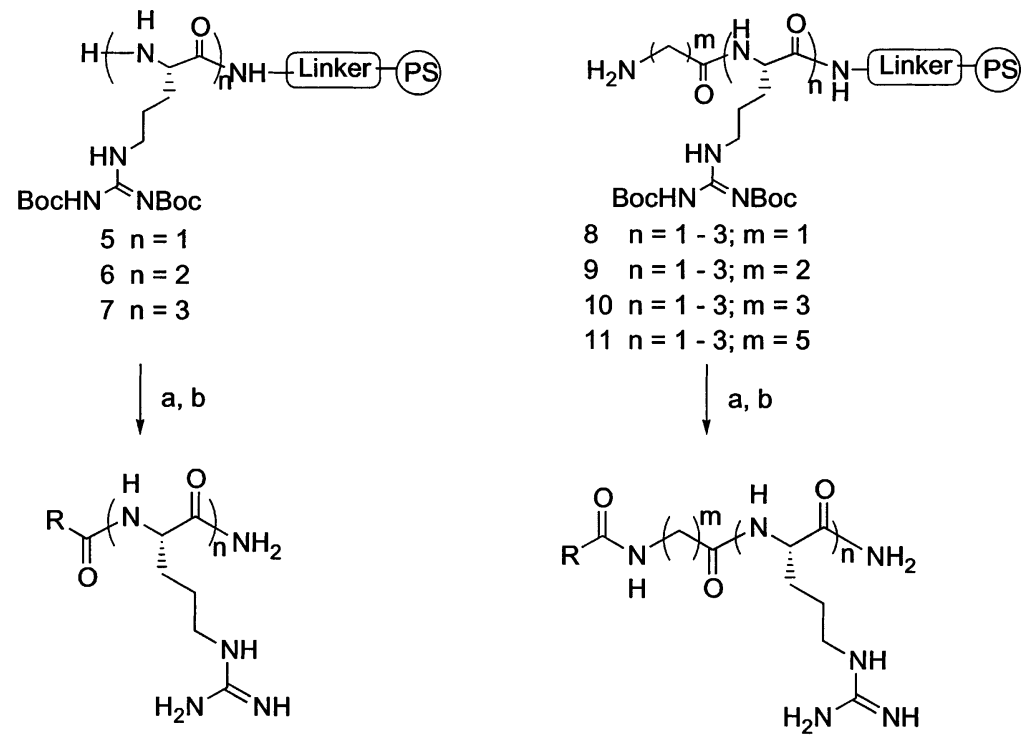

General structure without spacer

General structure with spacer

${ }^{a}$ Reagents and conditions: (a) For $\mathrm{R}=\mathrm{R}^{1}-\mathrm{R}^{4}$ : (see Table 1, Figure 3, 2 equiv), DIC (2 equiv), $\mathrm{HOBt}$ ( 2 equiv), $\mathrm{CH}_{2} \mathrm{Cl}_{2} / \mathrm{DMF}$. For $\mathrm{R}=\mathrm{R}^{4}:$ cholesteryl chloroformate (2 equiv), pyridine (4 equiv), DMAP (2 equiv), $\mathrm{CH}_{2} \mathrm{Cl}_{2} / \mathrm{DMF}$. (b) $90 \% \mathrm{TFA} / \mathrm{CH}_{2} \mathrm{Cl}_{2}$.

Transfection compounds containing three arginines all bound DNA (C5-8, D5-8, E5-7, F5-8, G5-7), except again for two compounds with cholesterol tails (E8 and G8). Thus, the binding activity of the cationic lipids increased as the 


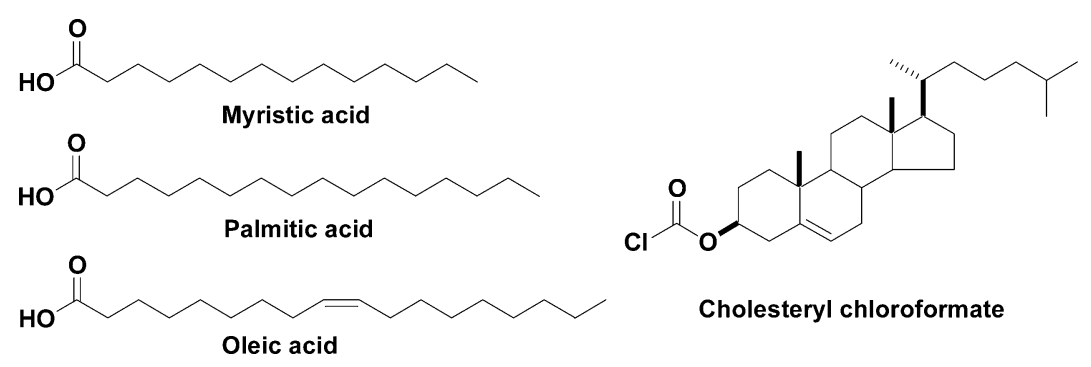

Figure 3. Carboxylic acids (hydrophobic tails) used for the synthesis of the transfection compound library.
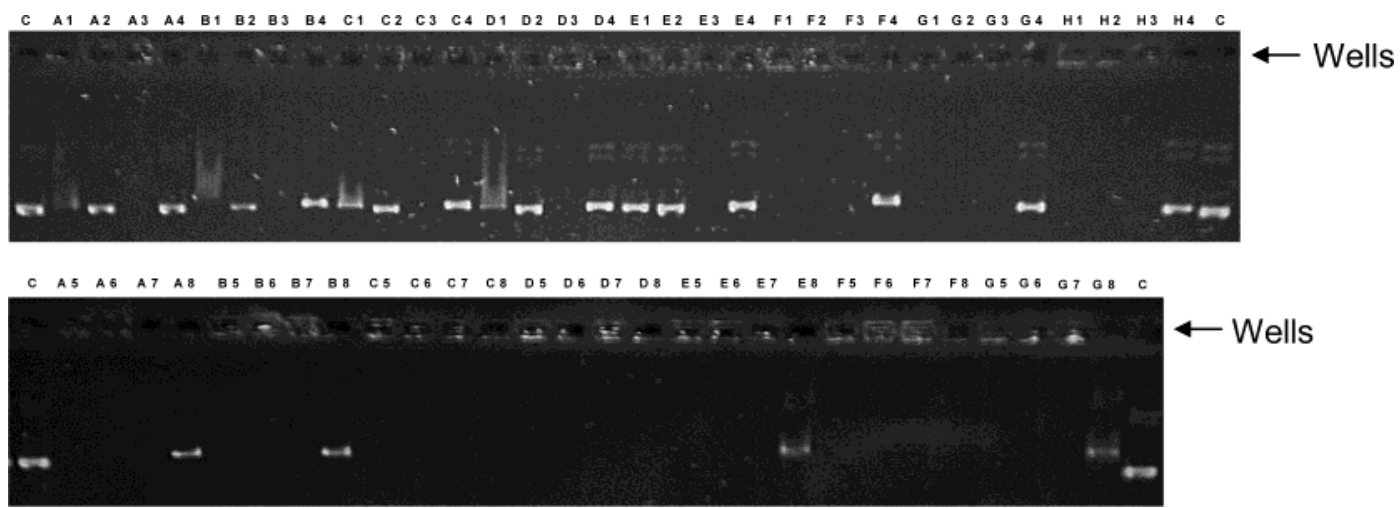

Figure 4. Single-bead gel retardation assay (pEGFPLuc, $0.1 \mu \mathrm{g}$ ) complexes; lanes marked "c"= control, DNA without cationic lipid. The presence of a band below the well indicates that the DNA has migrated and, thus, has not been bound by the transfection compound.

positive charge of the backbone increased, going from one to three arginines in the headgroup, consistent with the stronger electrostatic interaction with the negatively charged DNA phosphate groups. Cationic lipids with cholesterol tails tended to have weaker binding activity than those with aliphatic tails.

Single-Bead Transfection Screening. To evaluate the transfection activity of compounds derived from a single bead (Table 1), the compounds were mixed with the lipid dioleyl L- $\alpha$-phosphatidylethanolamine (DOPE, $25 \mu \mathrm{g}$ ), vortexed, and sonicated to form a liposome. DOPE was included as a colipid with the cationic lipids used in this study because it helps to promote a phase transition in liposomal structure, which is thought to promote the escape of DNA from transfection complexes when in the cytosol. ${ }^{18}$ The liposome was mixed with plasmid DNA $(0.1 \mu \mathrm{g})$ encoding $\beta$-galactosidase, and the transfection activity was determined on the human fibroblast cell line HEK293T. The assay was performed on all the compounds simultaneously, determining $\beta$-galactosidase enzymatic activity in a 96-well plate format, and compared to commercially available transfection reagent Effectene (Figure 5). Assays for $\beta$-galactosidase have the advantage of there being little cellular background.

The majority of cationic lipids screened did not mediate transfection under the conditions employed, but several of the lipids did have significant transfection activity. A4 gave a transfection level of $106 \%$, as compared to the control (100\%). C4, D4, E4, G4, H4, A8, and C8 were able to transfect HEK293T cells at 80\% efficiency, as compared to Effectene. Cholesterol derivatives with one, two, or three arginines were clearly more active than those with aliphatic tails, and some had an activity comparable to Effectene. Cationic lipids containing a cholesterol tail and one or two arginine headgroups gave higher transfection efficiencies than those containing three arginine groups. The spacer did not
Table 1. Cationic Lipids Generated from Scheme 3

\begin{tabular}{llllllllll}
\hline compound $^{a}$ & \multicolumn{1}{c}{$\mathbf{1}$} & \multicolumn{1}{c}{$\mathbf{2}$} & $\mathbf{3}$ & $\mathbf{4}$ & $\mathbf{5}$ & $\mathbf{6}$ & $\mathbf{7}$ & $\mathbf{8}$ \\
\hline A & Arg, $n$ & 1 & 1 & 1 & 1 & 2 & 2 & 2 & 2 \\
& spacer, $m$ & 0 & 0 & 0 & 0 & 3 & 3 & 3 & 3 \\
& tail, R & C14 & C16 & C18 & Chol & C14 & C16 & C18 & Chol \\
B & Arg, $n$ & 1 & 1 & 1 & 1 & 2 & 2 & 2 & 2 \\
& spacer, $m$ & 1 & 1 & 1 & 1 & 5 & 5 & 5 & 5 \\
& tail, R & C14 & C16 & C18 & Chol & C14 & C16 & C18 & Chol \\
C & Arg, $n$ & 1 & 1 & 1 & 1 & 3 & 3 & 3 & 3 \\
& spacer, $m$ & 2 & 2 & 2 & 2 & 0 & 0 & 0 & 0 \\
& tail, R & C14 & C16 & C18 & Chol & C14 & C16 & C18 & Chol \\
D & Arg, $n$ & 1 & 1 & 1 & 1 & 3 & 3 & 3 & 3 \\
& spacer, $m$ & 3 & 3 & 3 & 3 & 1 & 1 & 1 & 1 \\
& tail, R & C14 & C16 & C18 & Chol & C14 & C16 & C18 & Chol \\
E & Arg, $n$ & 1 & 1 & 1 & 1 & 3 & 3 & 3 & 3 \\
& spacer, $m$ & 5 & 5 & 5 & 5 & 2 & 2 & 2 & 2 \\
& tail, R & C14 & C16 & C18 & Chol & C14 & C16 & C18 & Chol \\
F & Arg, $n$ & 2 & 2 & 2 & 2 & 3 & 3 & 3 & 3 \\
& spacer, $m$ & 0 & 0 & 0 & 0 & 3 & 3 & 3 & 3 \\
& tail, R & C14 & C16 & C18 & Chol & C14 & C16 & C18 & Chol \\
G & Arg, $n$ & 2 & 2 & 2 & 2 & 3 & 3 & 3 & 3 \\
& spacer, $m$ & 1 & 1 & 1 & 1 & 5 & 5 & 5 & 5 \\
& tail, R & C14 & C16 & C18 & Chol & C14 & C16 & C18 & Chol \\
H & Arg, $n$ & 2 & 2 & 2 & 2 & & & & \\
& spacer, $m$ & 2 & 2 & 2 & 2 & - & - & - & - \\
& tail, R & C14 & C16 & C18 & Chol & & & & \\
\hline
\end{tabular}

${ }^{\mathrm{a}} n=$ number of arginine units, $m=$ number of methylene units in spacer ( $m=0$, compound without linker), $\mathrm{R}=$ hydrophobic tails.

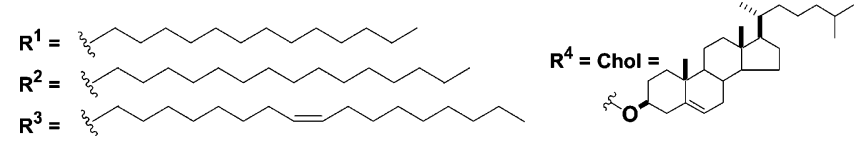

generally affect transfection efficiency for compounds with one- or two-arginine groups and a cholesterol tail; however, the transfection efficiency of the tri-arginine derivatives decreased when the length of spacer increased (Figure 5). The transfection patterns observed above relate not only to DNA delivery efficiency but also to cell toxicity, and thus, 


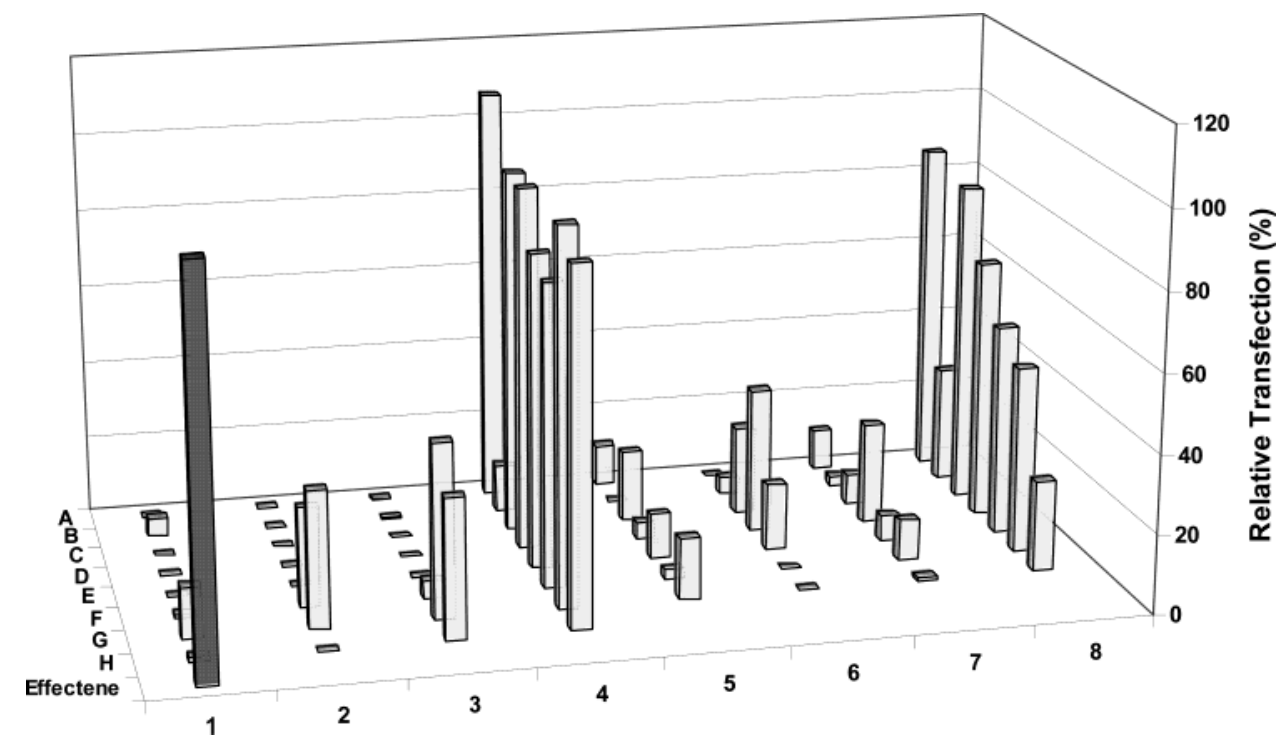

Figure 5. Transfection activities of synthetic compounds at the single-bead level. Liposomes from the compound and DOPE were mixed with DNA and incubated with HEK293T cells for $48 \mathrm{~h}$. Transfection activity was determined by a fluorimetric assay for $\beta$-galactosidase. $100 \%$ is the fluorescent signal from Effectene transfection and $0 \%$, from control wells.

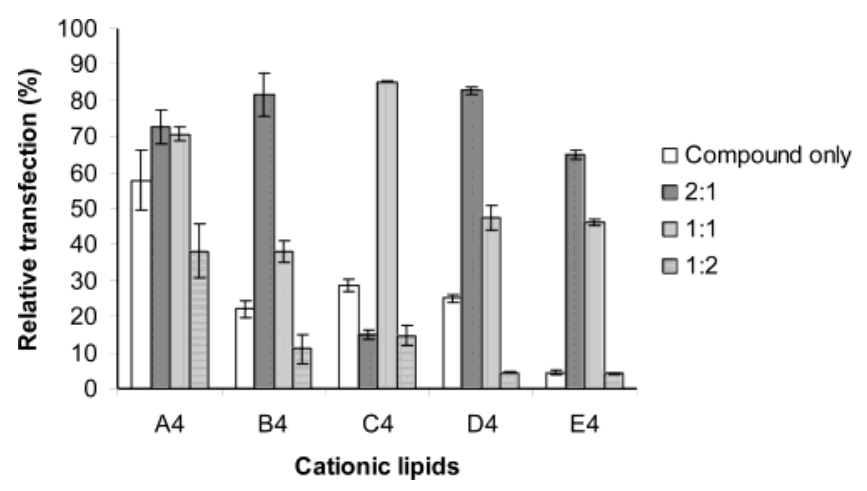

Figure 6. Effect of cationic lipid/DOPE ratio on transfection activity. DOPE and five of the most active cationic lipids were mixed at various ratios. Liposomes were formed, mixed with DNA, and incubated with HEK293T cells for $48 \mathrm{~h}$. Transfection activity was determined by a fluorimetric assay for $\beta$-galactosidase. $100 \%$ is the fluorescent signal from Effectene transfection and $0 \%$, from wells without transfection agent. Means from duplicate measurements are shown \pm 1 SD.

some of the compounds that did not produce efficient transfection were observed microscopically to cause cell death, presumably through a detergent-type activity disrupting the cell membranes. Compounds with a cholesterol tail were observed to cause little toxicity, as compared to those with aliphatic tails, compounds with three arginines, and long spacer units being particularly toxic.

It should be noted that some of the most active compounds with respect to transfection, containing one arginine and a cholesterol tail, did not appear to bind DNA in the gel retardation assay (Figure 4). This shows that it is important not to discard potential transfection compounds on the basis of this very widely used assay. The presence of DOPE in the transfection assay may increase DNA binding activity of these compounds, although we showed later that $\mathbf{A 4}$ has significant transfection activity even without the addition of the co-lipid DOPE (Figure 6).

Transfection Optimization. To optimize the transfection efficiency, accurate quantification of the compounds was needed. The synthesis of the cationic lipid series $(\mathbf{A 4}-\mathbf{E 4})$ with the highest transfection activity was therefore scaled up, and various parameters that could affect transfection activity were investigated.

Different Cationic Lipid/DOPE Ratios. The formulation of cationic liposomes (cationic lipid and co-lipid ratios) can have a crucial effect on the transfection efficiency. ${ }^{19}$ Studies on cells in culture clearly show that liposomes composed of an equimolar mixture of co-lipid DOPE and cationic lipids (e.g. $N$-[1-(2,3-dioleyloxy)propyl]- $N, N, N$-trimethylammonium chloride (DOTMA), 1,2-dioleyloxy-3-(trimethylammonio)-propane (DOTAP)) can mediate higher levels of transfection than those without DOPE or those with different helper lipids, such as 1,2-dioleoyl-sn-glycero-3-phosphatidylcholine (DOPC) ${ }^{20}$ In contrast, in vivo cholesterol-containing lipoplexes have shown higher biological activity, as compared to complexes with DOPE. ${ }^{21}$ To maximize the transfection activity of $\mathbf{A 4}-\mathbf{E} \mathbf{4}$, different ratios of cationic lipids to DOPE were examined. Transfection was carried out using four different cationic lipid/DOPE ratios (1:1, 1:2, 2:1, and without DOPE). DOPE was usually important for these compound libraries to obtain high transfection activity (Figure 6), but A4 was an exception, giving high transfection activity without DOPE. For four of the five lipids, a 2:1 ratio of lipid/DOPE was optimal.

Liposome Formation. The method of liposome formulation is undoubtedly important for transfection activity. ${ }^{22-24}$ DOPE and the cationic lipid were mixed in organic solvents, the solvent was evaporated, and the dried film was resuspended in PBS by vortex-mixing to produce multilamellar vesicles, which are broken by sonication into small unilamellar vesicles. The transfection activity of these two vesicle forms, produced from our cationic lipids, was determined. In both cases, cationic lipid was mixed with DOPE at a weight ratio of 1:1. All the cationic liposomes gave higher transfection efficiency when the liposomes were formulated by vortex-mixing and sonication rather than by vortex-mixing alone (Figure 7). Thus, for DOPE complexes with the 


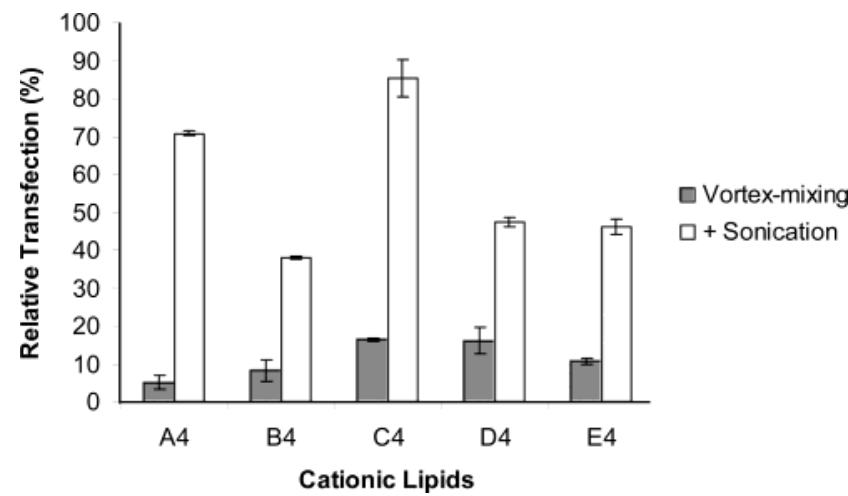

Figure 7. Effect of liposome formulation on transfection activity. Liposomes from five of the most active cationic lipids and DOPE were formed (a) by vortex-mixing alone, or (b) by sonication after vortex-mixing. Lipoplexes that were formed by mixing the liposomes and DNA were incubated with HEK293T cells for $48 \mathrm{~h}$. Transfection activity was determined by a fluorimetric assay for $\beta$-galactosidase. $100 \%$ is the fluorescent signal from Effectene transfection and $0 \%$ from wells without transfection. Means from duplicate measurements are shown $\pm 1 \mathrm{SD}$.

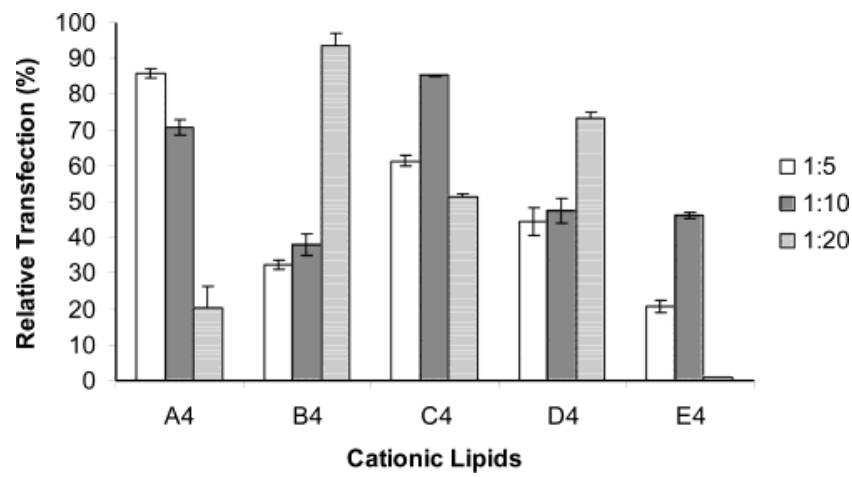

Figure 8. Effect of DNA/cationic lipid ratio on transfection activity. Liposomes of cationic lipid and DOPE were mixed with DNA at various DNA/cationic lipid ratios (w/w) and incubated with HEK293T cells for $48 \mathrm{~h}$. Means from duplicate measurements are shown \pm 1 SD.

cationic lipids containing one arginine group and a cholesterol tail, small unilamellar vesicles were more active than multilamellar vesicles.

DNA/Liposome Ratios. One reason the ratio of DNA to liposome is important is because of the change in charge of the lipoplexes. An overall positive charge promotes interaction with the negatively charged cell surface. The liposomes were therefore incubated with DNA at three different weight ratios, and transfection activity was determined (Figure 8). Changing the DNA ratio produced wide variations in transfection activity. Although the five cationic lipids differed only in the length of the spacer and had the same charge, the effect of different DNA ratios varied greatly for different lipids, suggesting that it is not simply the overall lipoplexes' charge that determines the optimal ratio.

Overall, the results of the initial optimization of the transfection activity of these compounds indicated that small changes in liposome composition can have dramatic effects on activity. Initial screens of libraries under one condition may well miss transfection compounds that would be highly active under other conditions. For the compounds synthesized here with one arginine and a cholesterol tail, a lipid/DOPE

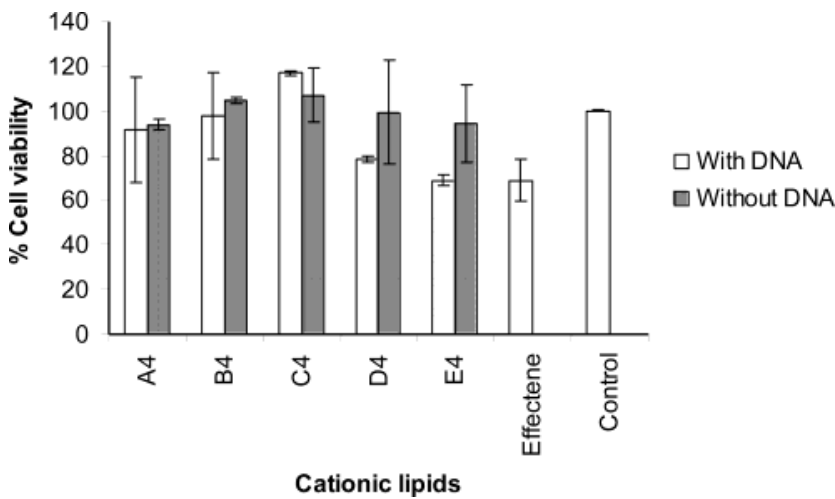

Figure 9. Effect of transfection compounds on cell metabolic activity. Liposomes of cationic lipid and DOPE were formed and added with or without DNA to HEK293T cells for $24 \mathrm{~h}$. Cell metabolic activity was determined by an MTT assay.

ratio of 2:1 and small unilamellar vesicles were best, but clearly, optimal lipid/DNA ratios must be determined empirically.

Transfection Cytotoxicity. To assess the relationship between cytotoxicity and gene expression efficiency, the toxicity of the cationic lipids (A4-E4) was determined by measuring changes in cell metabolic activity (MTT assay) $)^{25}$ (Figure 9). Cytotoxicity of A4-E4 was generally reduced in the absence of DNA. A4, B4, and C4 showed little cytotoxicity, but the cytotoxicity of D4 and E4 with the longer spacers was slightly greater, but still comparable to Effectene. Thus, this reduction in metabolic activity should not inhibit the application of these transfection compounds.

In conclusion, a solid-phase approach to prepare libraries of cationic lipids and assay compounds for transfection activity at the single-bead level has been developed and allowed members of the library to be identified that have the potential to be better than many currently available transfection reagents. Lipids with a one-arginine headgroup and a cholesterol tail were found to be the most active, even though their DNA binding strength was weak, as determined by a gel-retardation assay, whereas they displayed minimal cytotoxicity, showing that it is important not to discard potential transfection compounds on the basis of this very widely used assay. This approach enables libraries of thousands of compounds to be rapidly prepared and screened for potential in gene therapy applications. The efficient screening of "spotting" compounds cleaved from single beads into a microarray type format on a glass slide ${ }^{26}$ would allow much faster analysis of transfection activity against different cell-types, and this is an approach being developed and showing much promise in our laboratories.

\section{Experimental Section}

General Information. Low-resolution mass spectra were recorded on a VG platform quadrupole electrospray ionization mass spectrometer. High-resolution electrospray mass spectra were recorded on a Bruker Apex III FT-ICR mass spectrometer. Reversed-phase analytical HPLC (RP-HPLC) was performed using a Hewlett-Packard HP1100 Chemstation, equipped with a Phenomenex $\mathrm{C}_{18}$ prodigy $5-\mu \mathrm{m}$ (150 $\mathrm{mm} \times 3.0 \mathrm{~mm}$ i.d.) column, with an ELS detector. Starting materials and reagents were purchased from commercial 
suppliers and used without further purification. High-loading beads (2) were synthesized according to published procedures. $^{8}$

Synthesis of Transfection Compounds on High-Loading Beads. 1. Attachment of the Fmoc Knorr Linker onto High-Loading Beads. The Fmoc Knorr linker (3) (0.44 g, $0.81 \mathrm{mmol})$ was dissolved in $\mathrm{CH}_{2} \mathrm{Cl}_{2} / \mathrm{DMF}(2: 1,4 \mathrm{~mL})$. DIC $(0.13 \mathrm{~mL}, 0.81 \mathrm{mmol})$ and HOBt $(0.11 \mathrm{~g}, 0.81 \mathrm{mmol})$ were added. This mixture was left to stand for $10 \mathrm{~min}$. This solution was then added to aminomethyl polystyrene highloading dendrimer resin generation 1.0 (2) ( $0.16 \mathrm{~g}, 0.54$ $\mathrm{mmol}$ ), and the suspension was shaken overnight. The resulting resin was washed with $\mathrm{CH}_{2} \mathrm{Cl}_{2}$, DMF, $\mathrm{MeOH}$, $\mathrm{DMF}$, and $\mathrm{CH}_{2} \mathrm{Cl}_{2}(3 \times 2 \mathrm{~mL}$ each $)$ and dried under vacuum.

2. Synthesis of Arginine Scaffold-Bound Resin (5-7). The mono-arginine scaffold resin $\mathbf{5}$ was synthesized by the coupling of resin 4 (0.28 g, $0.45 \mathrm{mmol})$ with Fmoc-Arg$(\mathrm{Boc})_{2}-\mathrm{OH}(0.46 \mathrm{~g}, 0.77 \mathrm{mmol})$, DIC $(0.12 \mathrm{~mL}, 0.77 \mathrm{mmol})$, and $\mathrm{HOBt}(0.10 \mathrm{~g}, 0.77 \mathrm{mmol})$ in $\mathrm{CH}_{2} \mathrm{Cl}_{2} / \mathrm{DMF}(2: 1,4 \mathrm{~mL})$. This resin was treated with $20 \%$ piperidine in DMF $(5 \mathrm{~mL})$ for $10 \mathrm{~min}$. The resulting resin was washed with DMF, $\mathrm{MeOH}$, and $\mathrm{CH}_{2} \mathrm{Cl}_{2}(3 \times 5 \mathrm{~mL}$ each $)$ and dried under vacuum to give resin $\mathbf{5}$. Bis-arginine resin $\mathbf{6}$ was prepared by reacting resin $5(0.38 \mathrm{~g}, 0.46 \mathrm{mmol})$ with Fmoc-Arg$(\mathrm{Boc})_{2}-\mathrm{OH}(0.42 \mathrm{~g}, 0.70 \mathrm{mmol})$ using DIC $(0.11 \mathrm{~mL}, 0.70$ mmol) and HOBt $(0.09 \mathrm{~g}, 0.70 \mathrm{mmol})$ in $\mathrm{CH}_{2} \mathrm{Cl}_{2} / \mathrm{DMF}$ (2: 1, $4 \mathrm{~mL}$ ). The Fmoc protecting group was removed to afford resin 6 . This synthetic method was repeated for preparation of tris-arginine scaffold bound resin 7.

3. Synthesis of Arginine Scaffold Bound Resin with Spacer (8-11). These resins were synthesized according to the general procedure for the coupling of Fmoc amino acids. Typically, the spacer moiety was introduced by coupling to the arginine scaffold resins 5-7 (35-45 mg) with a Fmoc amino acid spacer (1.5 equiv) (Figure 2) using DIC (1.5 equiv) and $\mathrm{HOBt}$ (1.5 equiv) in $\mathrm{CH}_{2} \mathrm{Cl}_{2} / \mathrm{DMF}(2: 1,2 \mathrm{~mL})$. The resulting resins were then Fmoc-deprotected by treating with $20 \%$ piperidine in DMF. These resins were washed with $\mathrm{DMF}, \mathrm{MeOH}$, and $\mathrm{CH}_{2} \mathrm{Cl}_{2}(3 \times 2 \mathrm{~mL}$ each $)$ and dried under vacuum.

4. Synthesis of Arginine-Containing Cationic Liposomes without Spacer (A1-4, F1-4 and C5-8). These compounds were synthesized as shown in Scheme 3. The resins 5-7 (5-7 mg) were reacted with the carboxylic acids (Figure 3) (2 equiv), DIC (2 equiv), and HOBt (2 equiv) in $\mathrm{CH}_{2} \mathrm{Cl}_{2} / \mathrm{DMF}(5: 1,0.5 \mathrm{~mL})$. The suspension was shaken for $2 \mathrm{~h}$ and washed with $\mathrm{CH}_{2} \mathrm{Cl}_{2}, \mathrm{MeOH}, \mathrm{DMF}, \mathrm{MeOH}$, and $\mathrm{CH}_{2} \mathrm{Cl}_{2}(3 \times 0.5 \mathrm{~mL}$ each $)$ and dried under vacuum for $2 \mathrm{~h}$. Where the hydrophobic tail was cholesterol, the arginine scaffold resins $(5-7,5-7 \mathrm{mg})$ were reacted with a solution of cholesteryl chloroformate ( 2 equiv), pyridine (4 equiv), and DMAP (2 equiv) in $\mathrm{CH}_{2} \mathrm{Cl}_{2} / \mathrm{DMF}(5: 1,0.5 \mathrm{~mL}$ ), and the suspension was shaken for $4 \mathrm{~h}$. The resulting resin was washed with $\mathrm{CH}_{2} \mathrm{Cl}_{2}, \mathrm{MeOH}$, DMF, $\mathrm{MeOH}$, and $\mathrm{CH}_{2} \mathrm{Cl}_{2}$ (3 $\times 0.5 \mathrm{~mL}$ each) and dried under vacuum for $2 \mathrm{~h}$. This resin was reacted with a solution of $90 \%$ TFA in $\mathrm{CH}_{2} \mathrm{Cl}_{2}(0.2 \mathrm{~mL})$. The suspension was shaken for $2 \mathrm{~h}$, and the cleaved product in solution was collected. The solvents were removed in vacuo and further dried for $2 \mathrm{~h}$. The resulting products were dissolved in $\mathrm{MeOH} / \mathrm{CH}_{2} \mathrm{Cl}_{2}$, filtered through cotton wool, and dried under vacuum for $2 \mathrm{~h}$.

5. Synthesis of Arginine-Containing Cationic Liposomes with Spacers (B1-8, C1-8, D1-8, E1-8, F5-8, G1-8, and H1-4). The syntheses of these compounds were performed as described above, with the exception that the starting materials used were resin 8-11 (Scheme 3), which contained a spacer.

Cleavage of Compounds from the Resin. The resin (1 bead) was loaded into a $200-\mu \mathrm{L}$ vial insert, which was placed in a $1.5-\mathrm{mL}$ vial. A solution of $90 \% \mathrm{TFA} / \mathrm{CH}_{2} \mathrm{Cl}_{2}(50 \mu \mathrm{L})$ was added, and the vial was sealed with a cap and shaken for $2 \mathrm{~h}$. The solvents were removed under vacuum. The resulting product was redissolved in $\mathrm{MeOH}(2 \times 0.1 \mathrm{~mL})$ and filtered by passing through cotton wool. The solvent was removed under a stream of nitrogen, and the desired product was further dried under vacuum for $2 \mathrm{~h}$.

Gel-Retardation Assay. Plasmid DNA (pEGFPLuc, $1 \mu \mathrm{L}$, $0.1 \mu \mathrm{g} / \mu \mathrm{L}$ ) was incubated with the single-bead (36 nmol/ bead) cleaved compound in $4 \mu \mathrm{L}$ of phosphate buffered saline (PBS) (pH 7.4) for $30 \mathrm{~min}$. The DNA/cationic lipid complex was mixed with $40 \%(\mathrm{w} / \mathrm{v})$ sucrose in water $(5 \mu \mathrm{L})$ and loaded onto a $1 \%$ agarose gel $(0.5 \times$ TBE buffer). The gel was run at $200 \mathrm{~V}, 400 \mathrm{~mA}$ for $90 \mathrm{~min}$, and the DNA bands were visualized by ethidium bromide staining.

Single-Bead Transfection Screening. 1. Liposome Formation. DOPE $(10 \mu \mathrm{L}, 25 \mu \mathrm{g} / 10 \mu \mathrm{L})$ in $\mathrm{CHCl}_{3}$ was added to the dry compound cleaved from single beads, and the organic solvent was removed under vacuum (not less than 2 h). The resulting film was hydrated with PBS buffer $(10 \mu \mathrm{L}$, $\mathrm{pH}$ 7.4) at room temperature for $1 \mathrm{~h}$. The liposome was then sonicated at room temperature for $2 \times 20 \mathrm{~min}$ and stored at $4{ }^{\circ} \mathrm{C}$ for $24 \mathrm{~h}$ prior to use.

2. Transfection of HEK293T Cells. HEK293T (human embryonic kidney) cells were grown in DMEM supplemented with $10 \%$ heat-inactivated fetal calf serum, penicillin (100 units $/ \mathrm{mL})$, streptomycin $(100 \mu \mathrm{g} / \mathrm{mL})$, and L-glutamine $(4 \mathrm{mM})$ at $37{ }^{\circ} \mathrm{C}$ under $5 \% \mathrm{CO}_{2}$. For transfection, $1.8 \times 10^{4}$ cells/well were seeded in medium $(140 \mu \mathrm{L})$ in a 96-well culture plate to give $50-70 \%$ confluency for use the next day. The growth medium was removed and replaced with $100 \mu \mathrm{L}$ of serum-free medium (AIM-V, Sigma). Liposome complexes $(10 \mu \mathrm{L})$ were added to plasmid DNA (encoding $\beta$-galactosidase, $0.2 \mu \mathrm{L}, 0.5 \mu \mathrm{g} / \mu \mathrm{L}$ ) and incubated at room temperature for $30 \mathrm{~min}$. DNA/liposome complexes were added to the cells ( $10 \mu \mathrm{L} /$ well contained DNA $0.1 \mu \mathrm{g} / \mathrm{well})$, and the cells were incubated at $37^{\circ} \mathrm{C}$ under $5 \% \mathrm{CO}_{2}$ for 48 $\mathrm{h}$ without removing the transfection mixture. For transfections with Effectene (Qiagen), enhancer $(1.6 \mu \mathrm{L})$ was added to plasmid DNA $(0.2 \mu \mathrm{g}, 0.5 \mu \mathrm{L})$ in EC buffer $(60 \mu \mathrm{L})$. The mixture was vortexed for $2 \mathrm{~s}$. After $3 \mathrm{~min}, 5 \mu \mathrm{L}$ Effectene was added and the mixture was vortexed for $10 \mathrm{~s}$. After 7 min, serum-free medium $(350 \mu \mathrm{L})$ was added, the mixture was mixed by pipette (up and down twice), and $50 \mu \mathrm{L}$ of DNA/Effectene complex was added to the cells in each well. $\beta$-Galactosidase expression was determined with the FluoReporter LacZ/Galactosidase Quantitation kit (Molecular Probes) according to the manufacturer's instructions, with the reaction developed for $10 \mathrm{~min}$ at room temperature. 
Transfection efficiency was calculated as a percentage relative to the commercially available transfection reagent Effectene, after subtracting the value of untransfected cells.

Transfection Cytotoxicity. Cytotoxicity was evaluated using 3-(4,5-dimethylthiazol-2-yl)-2,5-diphenyl tetrazolium bromide reagent (MTT test). Cells were seeded in 96-well plates at $1 \times 10^{4}$ cells/well. The growth medium was removed the next day and replaced with $100 \mu \mathrm{L}$ of serumfree medium (AIM-V, Sigma). Cationic liposome/DNA complexes and Effectene were prepared as described in the transfection procedure and added to duplicate wells and the plates were incubated at $37{ }^{\circ} \mathrm{C}$ under $5 \% \mathrm{CO}_{2}$ for $24 \mathrm{~h}$. The medium was then removed and replaced with a phenol redfree medium $(90 \mu \mathrm{L})$. MTT $(3 \mathrm{mg} / \mathrm{mL})$ was added $(10 \mu \mathrm{L} /$ well) to the cells, followed by MTT solubilization solution (Sigma) $(100 \mu \mathrm{L})$ to dissolve the resulting crystals, and the absorbance was measured at $570 \mathrm{~nm}$ on a microplate reader (Bio-Rad). The change in metabolic activity was calculated as ( $\mathrm{A}_{570}$ with compound/ $\mathrm{A}_{570}$ without compound).

Acknowledgment. B.Y. thanks Ramkhamhaeng University for a studentship. M.B. thanks the BBSRC. M.H. is supported by the Medical Research Council and T.E., by Cancer Research U.K.

Supporting Information Available. Data on library members A1-F8. This material is available free of charge via the Internet at http://pubs.acs.org.

\section{References and Notes}

(1) (a) Osborn, H. M. I.; Khan, T. H. Tetrahedron 1999, 55, 1807-1850. (b) Lou, B. DDT 2001, 6, 1288-1294.

(2) (a) Furka, A.; Sebeysten, F.; Asgedom, M.; Dibo, G. Int. J. Pept. Protein Res. 1991, 37, 487-493. (b) Hughes, I.; Hunter, D. Curr. Opin. Chem. Biol. 2001, 5, 243-247.

(3) (a) Selway, C. N.; Terrett, N. K. Bioorg. Med. Chem. 1996, 4, 645-654. (b) Yasukata, T.; Shindo, H.; Yoshida, O.; Sumino, Y.; Munekage, T.; Narukawa, Y.; Nishitani, Y. Bioorg. Med. Chem. Lett. 2002, 12, 3033-3036.

(4) Lam, K. S.; Lebl, M.; Krchnak, V. Chem. Rev. 1997, 97, 411-448.

(5) Swali, V.; Wells, N. J.; Langley, G. J.; Bradley, M. J. Org. Chem. 1997, 62, 4902-4903.

(6) Newkome, G. R.; Weis, C. D.; Childs, B. J. Des. Monomers Polym. 1998, 1, 3-14.

(7) Lebraton, S.; Newcombe, N.; Bradley, M. Tetrahedron Lett. 2002, 43, 2479-2482.

(8) Lebreton, S.; How, S. E.; Buchholz, M.; Yingyongnarongkul, B.; Bradley, M. Tetrahedron 2003, 59, 3945-3953.

(9) Liu, F.; Huang, L. J. Controlled Release 2002, 78, 259266.

(10) Caplen, N. J.; Alton, E. W.; Middleton, P. G.; Dorin, J. R.; Stevenson, B. J.; Gao, X.; Durham, S. R.; Jeffery, P. K.; Hodson, M. E.; Coutelle, C. Nat. Med. 1995, 1, 39-46.
(11) Futaki, S.; Ohashi, W.; Suzuki, T.; Niwa, M.; Tanaka, S.; Ueda, K.; Harashima, H.; Sugiura, Y. Bioconjugate Chem. 2001, 12, 1005-1011.

(12) Mitchell, D. J.; Kim, D. T.; Steinman, L.; Fathman, C. G.; Rothbard, J. B. J. Peptide Res. 2000, 56, 318-325.

(13) Byk, G.; Dubertret, C.; Escriou, V.; Frederic, M.; Jaslin, G.; Rangara, R.; Pitard, B.; Crouzet, J.; Wils, P.; Schwartz, B.; Scherman, D. J. Med. Chem. 1998, 41, 224-235.

(14) Obika, S.; Yu, W.; Shimoyama, A.; Uneda, T.; Miyashita, K.; Doi, T.; Imanishi, T. Bioorg. Med. Chem. Lett. 1997, 7, 1817-1820.

(15) Floch, V.; Legros, N.; Loisel, S.; Guillaume, C.; Guilbot, J.; Benvegnu, T.; Ferrieres, V.; Plusquellec, D.; Ferec, C. Biochem. Biophys. Res. Commun. 1998, 251, 360-365.

(16) Kawaura, C.; Noguchi, A.; Furuno, T.; Nakanishi, M. FEBS Lett. 1998, 421, 69-72.

(17) Lynn, D. M.; Anderson, D. G.; Putnam, D.; Langer, R. J. Am. Chem. Soc. 2001, 123, 8155-8156.

(18) Koltover, I.; Salditt, T.; Raedler, J. O.; Safinya, C. R. Science 1998, 281, 78-81.

(19) Pedroso de Lima, M. C.; Simoes, S.; Pires, P.; Faneca, H.; Duzgunes, N. Adv. Drug Delivery Rev. 2001, 47, 277-294.

(20) (a) Hui, S. W.; Langner, M.; Zhao, Y. L.; Hurley, E.; Chan, K. Biophys. J. 1996, 71, 590-599. (b) Mok, K. W. C.; Cullis, P. R. Biophys. J. 1997, 73, 2534-2545.

(21) (a) Wang, J.; Gao, X.; Xu, Y.; Barron, L.; Szoka, F. C. J. Med. Chem. 1998, 41, 2207-2215. (b) Hong, K.; Zheng, W.; Baher, A.; Papahadjopoulos, D. FEBS Lett. 1997, 400, 233-237. (c) Song, Y. K.; Liu, D. Biochim. Biophys. Acta 1998, 1372, 141-150.

(22) (a) Felgner, J. H.; Kumar, R.; Sridhar, C. N.; Wheeler, C. J.; Tsai, Y. J.; Border, R.; Ramsey, P.; Martin, M.; Felgner, P. L. J. Biol. Chem. 1994, 269, 2550-2561. (b) Balasubramaniam, R. P.; Bennett, M. J.; Aberle, A. M.; Malone, J. G.; Nantz, M. H.; Malone, R. W. Gene Ther. 1996, 3, 163172. (c) Wheeler, C. J.; Felgner, P. L.; Tsai, Y. J.; Marshall, J.; Sukhu, L.; Doh, S. G.; Hartikka, J.; Nietupski, J.; Manthorpe, M.; Nichols, M.; Plewe, M.; Liang, X.; Norman, J.; Smith, A.; Cheng, S. H. Proc. Natl. Acad. Sci. U.S.A. 1996, 93, 11454-11459.

(23) (a) Vigneron, J.-P.; Oudrhiri, N.; Fauquet, M.; Vergely, L.; Bradley, J.-C.; Basseville, M.; Lehn, P.; Lenh, J.-M. Proc. Natl. Acad. Sci. U.S.A. 1996, 93, 9682-9686. (b) Ghosh, Y. K.; Visweswariah, S. S.; Bhattacharya, S. FEBS Lett. 2000, 473, 341-344. (c) Fang, N.; Wang, J.; Mao, H.-Q.; Leong, K. W.; Chan, V. Colloids Surf., B 2003, 29, 233245.

(24) (a) Keil, O.; Bojar, H.; Prisack, H.-B.; Dall, P. Bioorg. Med. Chem. Lett. 2001, 11, 2611-2613. (b) Noguchi, S.; Hirashima, N.; Furuno, T.; Nakanishi, M. J. Controlled Release 2003, 88, 313-320. (c) Piperno-Neumann, S.; Oudar, O.; Reyneir, P.; Briane, D.; Cao, A.; Jaurand, M. C.; Naejus, R.; Kraemer, M.; Breau, J. L.; Taillandier, E. Biochim. Biophys. Acta 2003, 1611, 131-139.

(25) Denizot, F.; Lang, R. J. Immunol. Methods 1986, 89, 271277.

(26) Ziauddin, J.; Sabatini, D. M. Nature 2001, 411, 107-110. CC049945T 